\title{
ÁLBUNS DE GRAVURA \\ EDITADOS POR JULIO PACELLO NA \\ COLEÇÃO DO MUSEU UNIVERSITÁRIO \\ DE ARTE DA UFU
}

\author{
Marco Antonio Pasqualini de Andrade* \\ Universidade Federal de Uberlândia
}

\section{RESUMO}

Julio Pacello foi um importante editor de álbuns de gravura nas décadas de 1960 e 1970 , dos quais o MUnA - Museu Universitário de Arte da Universidade Federal de Uberlândia possui alguns exemplares. Este artigo discute sua presença no acervo do museu, tendo em vista as informações do inventário, dados de aquisição e de como determinam um recorte significativo ao ser pensados e expostos conjuntamente. Por fim, cabe discutir a contribuição do editor, sua trajetória e o legado de tais obras, analisando os exemplares citados e portanto, revelando seu valor e o território que ocupam dentro da instituição.

\section{PALAVRAS-CHAVE}

Gravura; Museu de Arte; Julio Pacello; acervo.

\begin{abstract}
Julio Pacello was an important publisher of artist's printed albums in the 1960s and 1970s, of which the Muna - University Art Museum of the Federal University of Uberlândia - has some copies. This article discusses its presence in the museum's collection, including inventory information, data acquisition and how to determine their significant role when investigated and displayed together. Finally, it focuses the contribution of the publisher, his history and the legacy of such works, analyzing some examples and thus revealing their value and the territory they occupy in the institution.
\end{abstract}

\section{KEY-WORDS}

Prints;Art Museum; Julio Pacello; collection.

" Doutor em Artes pela Universidade de São Paulo. Professor adjunto no Instituto e Artes da Universidade Federal de Uberlândia, onde atua nos cursos de graduação em Artes Visuais e Jornalismo, e nos cursos de mestrado em Artes e Arquitetura e Urbanismo. 


\section{Introdução'}

O Museu Universitário de Arte da Universidade Federal de Uberlândia abriu suas portas com a sua primeira exposição no final de 1998. Contava então com um acervo modesto de pouco menos de 100 obras adquiridas ao longo de várias décadas principalmente por doações de artistas que faziam exposições organizadas pelo Departamento de Artes Plásticas da universidade, que tinham sido acrescidas por um conjunto de aproximadamente 50 obras em gravura doadas pelo Banco Central do Brasil. Desde então, doações esporádicas individuais e alguns conjuntos de obras foram adquiridos sem uma política oficial de aquisição, mas com uma tendência subliminar voltada a obras em papel, predominantemente gravuras modernas e contemporâneas.

Durante o trabalho de elaboração de uma curadoria do acervo, conjuntamente com o coordenador na época, prof. Alex Miyoshi, foi identificada a existência de três álbuns de gravura editados por Julio Pacello. Ou seja, dentro de um acervo relativamente pequeno havia um conjunto singular que despertou uma curiosidade de pesquisa e aprofundamento, por se tratar de uma associação não inicialmente prevista como um paradigma dentro do museu.

Embora não haja ainda uma catalogação definitiva do acervo do MUnA, foram executados dois inventários de obras, um em 2009, coordenado pela pro$f^{\text {a }}$. Luciene Lehmkul, e um em 20I2, na gestão do prof. Paulo Buennoz. A partir dos dados desses dois inventários, iniciou-se um processo de tentativa de identificação de outras obras ou conjuntos de obras ligados às edições de Pacello, o que resultou na constatação da presença de fragmentos de mais 5 álbuns do editor. Ou seja, de fato há a presença significativa de um conjunto que merece ser estudado com atenção.

Dessa maneira, o presente texto tem por fim compreender o significado e o valor desse conjunto de obras, e assim ajudar a refletir sobre a coleção como um todo. Propõe-se, então, fazer uma primeira reflexão sobre tal questão.

$$
* * *
$$

A produção de gravuras artísticas e imagens múltiplas, desde sua origem, estão frequentemente vinculadas à ilustração de textos e ao formato livro, seja como um complemento de significado ou estabelecendo uma sequência ordenada de ideias.

Se o incunábulo xilográfico conseguia unir tipografia e xilogravura como um corpo coeso, o surgimento da gravura em metal como forma mais avançada de produção de imagens de qualidade acabou por separar a produção, sendo as gravuras anexadas em lâminas aos livros com nítida distinção de papel e impressão.

Além das ilustrações científicas e literárias, livros ou álbuns apenas de imagens foram tornando-se comuns, a exemplo de Os Capricho, de Goya (I799) ou a Viagem Pitoresca ao Brasil, de Rugendas (I825-1828). O modernismo recuperou o formato, seja com os livros ilustrados franceses ou com as edições expressionistas alemãs.

Essa proposta permanece válida na arte moderna e contemporânea, mas com uma maior independência das imagens, e existindo muitas vezes sob a forma de álbuns, normalmente constituídos por lâminas soltas, que são organizadas em pastas ou caixas.

\footnotetext{
O artigo é um desdobramento da pesquisa "Arte fora dos eixos: subsídios para a construção de uma história das artes visuais no Triângulo Mineiro e entorno", financiada pela FAPEMIG - Fundação de Apoio à Pesquisa do Estado de Minas Gerais (edital 2014). Trata-se de uma versão do trabalho apresentado no XXXIV Colóquio do Comitê Brasileiro de História da Arte, realizado em Uberlândia-MG em 2014.
} 
No Brasil, pode-se citar como pioneiros os álbuns de Oswaldo Goeldi: Dez gravuras em madeira (1930) e Cobra Norato (1937). Mais tarde, Carlos Scliar organizaria Trinta e cinco litografias (1942), com obras de Lívio Abramo, Aldo Bonadei, Clóvis Graciano, Manoel Martins, Oswald de Andrade Filho e Walter Levy com tiragem de 200 exemplares.

Editores como José Olympio, os Cem Bibliófilos, Hipocampo, Gráfico Amador e Philobiblion publicaram livros ilustrados por estampas de artistas modernos e criaram um campo de divulgação que se estendeu até a década de 1960, época em que se instalou a editora de Julio Pacello (Banat, 1996).

\section{Julio Pacello}

Argentino radicado no Brasil, foi um importante editor desses álbuns nas décadas de 1960 e 1970. Segundo José Mindlin, era:

Um homem alto, magro, tímido, tão silencioso quanto loquaz, pouco à vontade de terno e gravata, há muitos anos prematuramente envelhecido, com saúde precária mas não dando importância à doença, aparentando muito mais idade do que tinha.... (1979).

Nascido em 1931 em Buenos Aires, chegou ao Brasil em 1953 com 22 anos, e faleceu de enfarte em janeiro de 1977, durante uma viagem à Argentina. Mindlin comenta sobre uma série de características e atividades de Pacello, desde seu intenso relacionamento com personalidades da área cultural de diversos países, sua imensa capacidade de trabalho, a seu papel como antiquário e marchand, especialmente de objetos coloniais.

Segundo depoimento de Evandro Jardim (apud Banat, 1996: 50), Julio Pacello frequentava o ateliê de gravura da Escola de Belas Artes de São Paulo, por volta de 1957. Interessou-se por editar um livro de gravuras de Jardim (denominado Bahia), do qual foi impresso um protótipo no ateliê de Francesc Domingo Segura (Barcelona, I 893 - São Paulo, 1974), catalão que havia morado entre 1950 e 1951 em Buenos Aires.

A editora foi montada no início da década de 1960 nos fundos da casa do editor, na Rua Barão do Rego Barro n. 28, bairro de Campo Belo, próximo do Aeroporto de Congonhas, na cidade de São Paulo. A primeira edição data de 1964, e trata-se de um álbum de xilogravuras do artista gaucho Trindade Leal, que auxiliou Pacello nas primeiras impressões da editora.

Em 1967 iniciam-se os álbuns a partir de gravuras em metal, com impressão de Otto Grassmann, irmão mais velho de Marcelo Grassmann. Segundo Antonio Albuquerque (apud Banat: 1996:50-5I), a prensa para metal só seria adquirida no início da década de 1970. Albuquerque, que era motorista de Pacello desde 1966, acabou por aprender o ofício de impressor, e após 1972, quando imprimiu o álbum de Flávio de Carvalho, foi responsável, juntamente com Roberto Grassmann (que substituiu o irmão Otto após seu falecimento em 1969), por todas edições realizadas pelo editor.

Mindlin e Albuquerque afirmam que Pacello acompanhava de perto todas impressões, sendo ele mesmo responsável por algumas delas, com apuro e rigor, buscando a perfeição da edição. Mindlin declara que eram "edições de qualidade incomparavelmente superior a tudo quanto se havia feito no Brasil até então" (Mindlin, 1979).

Foram editados ao todo, entre 1964 e 1977, vinte e quatro álbuns de gravura, sendo o último a Antologia Gráfica de Renina Katz. Além disso, várias obras ficaram inacabadas, entre elas álbuns de: Evandro Jardim, Maciej Babinski, Vera Bocayuva Mindlin, Tereza Miranda, Francisco Stockinger, Octavio Araujo,Anestor, - 30 volume da Historia da Gravura, Pat Andrea e Guilhermo Roux (Banat, 1996). 
Além do fato de valorizar tanto artistas já consagrados como exemplares próximos da cultura popular, Mindlin destaca também um certo experimentalismo de suas edições:

Os álbuns de Renée Sasson, Liuba e Julio Plaza mostram, aliás, que Júlio, além de perfeccionista, e gráfico de grande competência e sensibilidade artística, não se limitou à divulgação da gravura. Buscava novos caminhos e novas formas de expressão. (Mindlin, 1979)

A fala do bibliófilo diz respeito a edições que não se limitaram á impressão de obras planares convencionais, mas que exploraram o relevo, a dobra, a tridimensionalidade, como outros tipos de múltiplos, que seriam valorizados no final da década de 1960 por exposições e galerias comerciais.

O conjunto de álbuns publicados por Julio Pacello contribuíram para a divulgação da gravura no Brasil e adquiriram importância significativa na construção de sua história, constituindo, dessa forma, um conjunto exemplar que guarda, além de cada obra e artista individuais, um vínculo especial com determinado contexto de época que se soma e valoriza a produção artística além de seu aspecto isolado e formal.

\section{Álbuns de Pacello no MUnA}

A partir dos inventários realizados, detectou-se que o MUnA - Museu Universitário de Arte da Universidade Federal de Uberlândia, possui três exemplares completos de álbuns publicados por Julio Pacello (com capa, textos, caixas, etc.): a Via Sacra de Mestre Nosa (1969); Objetos de Julio Plaza (1969); e a Suíte Gaucha de Carlos Scliar (1973).

Também foram identificadas, a partir de dados cruzados de datação e numeração da tiragem, imagens soltas da Pequena Bíblia de Raimundo de Oliveira (1966) (2 imagens das 15 originais); das Gravuras de Maciej Babinski (1967) (5 das 6 originais); Gravuras de Edith Behring de 1968 (9 das 10 originais); Gravuras de Darel, também de 1968 (3 das 12 originais), e algumas lâminas da Historia da Gravura no Brasil II, editada em 1969 (4 das 10 originais). É possível que algumas estampas de uma grande doação de Renina Katz, realizada recentemente e ainda não devidamente inventariadas, pertençam a um dos dois álbuns da artista, editados por Pacello em 1970 e 1977, contudo não há condições até o momento de tal identificação.

É preciso observar que o MUnA possui outros álbuns de gravura não editados por Pacello, entre eles: O Bestiário, de Rogério Scorzelli (1976); Telhados de Ouro Preto, de Carlos Scliar (1977); O Elogio da Xilo, de Maria Bonomi e Haroldo de Campos (1994); e Fragmentos, de Renina Katz e Ferez Khoury (2000). Tal fato insere os álbuns de Pacello em uma ordem maior, que será comentada mais adiante.

\section{Dados das obras}

Álbuns completos:

Via Sacra de Mestre Nosa (1969)

Texto de Maria Eugênia Franco; 15 xilogravuras.

Tiragem: 100 exemplares especiais, sobre papel colorido e com duas séries suplementares ( I a I00); 500 exemplares sobre papel colorido.

Obra do acervo do MUnA: Caixa com série completa, sem numeração de tiragem (Inv.: 2012.044). Adquirido em 2012 pela Fundação de Apoio Universitário da UFU. 
Série Gaucha de Scliar (1974)

Texto de Joaquim Cardozo; 9 linoleogravuras (3 coloridas "au pochoir").

Tiragem: I 5 exemplares (I/XV a XV/XV); 100 exemplares (I/I00 a I00/I00); 10 exemplares de colaborador (A a J). Editora César.

Obra do acervo do MUnA: Caixa com série completa, numeração da tiragem: 3/100 (Cat.: Fichas I2I.I a I21. 16; Tombo n. 2009. I I). Adquirido em 2009.

Objetos de Julio Plaza (1969)

Poema de Augusto de Campos; 12 lâminas impressas em serigrafia em cores com vincos e dobras.

Tiragem: 2 exemplares fora de comércio (A e B), com 4 séries suplementares; 100 exemplares ( $/ / 100$ a I00/I00); 30 exemplares fora de comércio ( $($ a $X X X)$.

Obra do acervo do MUnA: álbum completo, sem numeração da tiragem (Inv. 2012.045). Adquirido em 2012 pela Fundação de Apoio Universitário da UFU.

Lâminas soltas:

Pequena Bíblia de Raimundo de Oliveira (1966)

Palavras de Jorge Amado; 10 xilogravuras em cores (3 chapas cada).

Tiragem: 650 exemplares. Editora Cesar.

Obras do acervo do MUnA: Expulsão de Adão e Eva do paraíso (cat.: fich. 72) (verde, azul, preto); Passagem do Rio Vermelho (cat.: fich. 73) (preto, azul, magenta). Sem numeração de tiragem. Adquiridas em 2007 através de doação de Beatriz Rauscher (que, segundo depoimento, as adquiriu na década de 1980 do impressor Antonio Albuquerque).

Gravuras de Babinski (1967)

Texto de Marcelo Corção; 6 gravuras em cobre.

Tiragem: 5 exemplares coloridos a mão pelo autor (D a H); 50 exemplares em preto; 3 exemplares de colaborador ( $\mathrm{A}$ a $\mathrm{C}$ ) e $\mathrm{I} 0$ exemplares do artista ( $\mathrm{I}$ X $\mathrm{X}$ ). Placas inutilizadas.

Obras do acervo do MUnA: Número da tiragem: "álbum 6/50". (cat. 2008: fich. 00 I; fich. 003; fich. 009; fich. 0I0; fich. 0II). Adquirido em 1999 através de doação do Banco Central do Brasil.

Gravuras de Edith Behring (1968)

Poema de Walmir Ayala; 10 gravuras em cobre.

Tiragem: 10 exemplares fora de comércio ( $\mathrm{I}$ a $\mathrm{X}$ ); 100 exemplares ( $\mathrm{I}$ a I00), dos quais 25 fora de comércio; 6 exemplares de colaborador ( $A$ a $F$ ).

Obras do acervo do MUnA: Número da tiragem: VIII (Inv.: 20I2/00I); 63/I00 (Inv.: 20I2/007); 64/I00 
(Inv.: 20I2/006); 73/100 (Inv.: 20I2/002); 75/100

(Inv.: 20I2/009); 77/I00 (Inv.: 20I2/005); 80/100 (Inv.: 20I2/003); 83/I00 (Inv.: 20I2/008); 95/I00 (Inv.: 20I 2/004).Adquirido em 2012 pela Fundação de Apoio Universitário da UFU.

Gravuras de Darel (1968)

Texto de Clarice Lispector; 12 gravuras em cobre.

Tiragem: I 0 exemplares fora de comércio ( $\mathrm{l}$ a $\mathrm{X}$, acomp. de série suplementar e 10 rejeitadas $01 / 10$ a $10 / 10)$; I 0 exemplares fora de comércio ( $\mathrm{XI}$ a $\mathrm{XX}$, acomp. de série suplementar); 100 exemplares ( $1 / 100$ a 100/I00, sendo 23 fora de comércio); 6 exemplares de colaborador (A a $F)$.

Obras do acervo do MUnA: Número da tiragem: II (Inv.: 20I2/0I5 e Inv.: 20I2/0I7); 09/I0 (Inv.: 20I2/0I6). Adquirido em 2012 pela Fundação de Apoio Universitário da UFU.

Historia da Gravura no Brasil II (1969)

Texto de José Roberto Teixeira Leite; poema de Lélia Coelho Frota; 10 gravuras assinadas por Anna Letycia, Carlos Prado, Carlos Scliar, Farnese, Milton Dacosta, Octávio de Araújo, Regina Silveira, Renina Katz, Vera Chaves Barcellos e Wesley Duke Lee.

Tiragem: 50 exemplares fora de comércio (I a L, com série supl. em cores e papeis diferentes); 200 exemplares (I/200 a 200/200); 20 exemplares fora de comercio $(\mathrm{A}$ a $\mathrm{U})$; I 5 exemplares de colaboradores (marcados $\mathrm{E}$. C.). Editora Cesar.

Obras do acervo do MUnA: Sem título, de Octávio Araújo, número da tiragem: VI (Inv.: 2012/028) (obs.: no inventário, as fotografias dos números 2012/027 e 2012/028 estão trocadas); Sem título, de Vera Chaves Barcelos, número da tiragem 34/200 (Inv.: 20I2/030); Sem título, de Farnese, número da tiragem: XV (Inv.: 20 I 2/037); Sem título, de Anna Letycia, número da tiragem: 67/200 (Inv.: 2012/038). Adquirido em 2012 pela Fundação de Apoio Universitário da UFU.

\section{Sobre os álbuns completos}

Os três álbuns completos presentes no acervo do Museu universitário de Arte são bastante distintos entre si, concebidos por um artista da cultura popular, um gravador moderno e um artista experimental ligado aos novos meios de comunicação.

Mestre Noza² (Inocêncio Ferreira da Costa ou Inocêncio da Costa Nick) nasceu em Taguatinga do Norte, estado de Pernambuco, em 1987, e faleceu na

\footnotetext{
${ }^{2}$ No álbum Via Sacra, a capa traz o nome gravado "Noza" com o "z" grafado invertido, como se fosse um "s" anguloso. Pelos outros álbuns do artista, percebe-se que esse era um costume que repetia-se na grafia de "Juazeiro". Porém, na prancha de créditos, claramente aparece o nome "Nosa" com "s".
} 
cidade de São Paulo em 1983. Após uma caminhada em romaria até Juazeiro do Norte, muda-se para o Ceará, onde começa a executar rótulos de garrafas de aguardente, depois iniciando esculturas em madeira de santos (especialmente do Padre Cícero) e, na década de 1940, gravuras em madeira para folhetos em cordel. A partir da década de 1960 o Museu de Arte da Universidade do Ceará (MAUC) passa a acolher e divulgar seu trabalho, através de edições de suas gravuras e do interesse do artista Sérvulo Esmeraldo, que leva sua obra a França. Por seu intermédio, em 1965, Robert Morel editará em Paris uma primeira versão da Via Sacra, com 14 imagens e uma prancha contendo o título, que será impressa primeiramente com 22 exemplares, e depois em uma tiragem de 1000 (Casimiro, 200I).

A Via Sacra editada por Pacello em 1969, segue a mesma iconografia da primeira versão, contendo as mesmas imagens e posições, porém gravadas de modo sintético, como se vistas mais de perto, e os personagens representados atarracados (ao contrario das longilíneas figuras do álbum francês). Uma linha fecha o retângulo horizontal, cuja base confunde-se com o chão da cena. Outra singularidade é a utilização de papéis de seda coloridos como suporte, que confere uma proximidade às obras de cordel, e a existência de pequenos sinais ou manchas no fundo branco (inexistentes na edição de Morel).

Sobre sua obra, Leonor Amarante comenta:

Seu trabalho prova que na gravura popular os elementos tecnicamente rudes podem se harmonizar com o refinamento e a exata adequação de meios e mensagens, para atingir níveis expressivos de fruição estética. É inevitável associar Noza aos expressionistas alemães do grupo Die Brücke (A Ponte), especialmente em cenas alegóricas como a Via Crucis. Seu traço violento e expressivo já nasce autônomo, resultado de uma técnica precisa de sulcar a madeira. (Amarante, 1994: 12)

De fato, a gravação obedece a um padrão de sulcos e traços realizados de modo bruto e econômico, os mesmos de sua produção como santeiro, que geram uma imagem com semelhanças às primeiras xilogravuras medievais de cartas de baralho, e próximas ao gosto da vanguarda expressionista alemã.

É preciso lembrar que a valorização da cultura popular no Brasil tem início da década de 1930, por vários intelectuais brasileiros, mas de fato passa a integrar o repertório dos artistas na década de 1960, quando torna-se referência importante para as novas figurações da vanguarda das artes visuais.

Carlos Scliar nasceu em 1920 na cidade de Santa Maria, no Rio Grande do Sul, e faleceu no Rio de Janeiro em 200I.Após sua introdução artística em Porto Alegre, transfere-se para São Paulo, convivendo com artistas modernos da Família Artística Paulista. Após a Segunda Guerra Mundial funda em Porto Alegre, junto com Vasco Prado, o Clube de Gravura, quando desenvolve uma série de imagens relacionadas às tradições gauchas, dentro do programa regionalista e social do clube (Gonçalves, 2006; Salvatori, 20I I; Motter, 20 I3). No final da década de 1950 muda para o Rio de Janeiro, dedicando-se a uma obra de naturezas mortas, com bules e lamparinas, e paisagens, com caráter mais fragmentado e abstrato.

A Série Gaucha, publicada em 1974 por Pacello, é portanto uma retomada de seus temas regionalistas da época do Clube de Gravura. Joaquim Cardozo, no texto de introdução, fala sobre os três elementos básicos do álbum: pessoas, animais domésticos e utensílios, que nos apresentam elementos da atividade rural de seu estado como vistos em detalhe, seus hábitos e relações. Os retratos, com seus gestos e atitudes; o bestiário dos animais na apreensão doméstica; a "afeição ilimitada pelo objeto" (Cardozo, 1974).

Nas estampas da Série Gaucha, Scliar utiliza tanto as nuances de tons de uma única cor impressa, o contraste entre o preto e uma cor aplicada ao fundo 
(os camaieux descritos por Cardozo), quanto a utilização do pouchoir, na qual máscaras de cor são aplicadas à impressão em linoleografia. As linhas podem perfazer hachuras ou traços contínuos e o desenho, sintético, remete a um certo expressionismo dramático, com figuras alongadas e luzes contrastantes.

Júlio Plaza, espanhol nascido em Madri em 1938 e falecido em São Paulo em 2003, desenvolve sua trajetória a partir de uma escolha pelas formas abstratas, seriadas, construtivas, com as quais aproxima-se de estruturas ópticas, cinéticas, minimalistas. É com tais obras que viaja ao Brasil, acabando por fixar-se em São Paulo e onde percorre um caminho em direção aos novos meios de reprodução da imagem, da comunicação, e da linguística semiótica, que acabam por aproximá-lo às tendências desmaterializadas e conceituais.

Objetos, de 1969, é a primeira de uma série de colaborações entre Plaza e o poeta concreto Augusto de Campos. $O$ poeta descreve o projeto:

Serigrafadas pelo próprio Plaza, os "objetos" consistiam, cada qual, em duas folhas de papel superpostas e coladas, com um vinco central, formando páginas que, ao serem desdobradas, revelavam formas tridimensionais ao mesmo tempo geométricas e orgânicas, mediante um jogo estudado de cores. Algo que ficava "entre" o livro e a escultura. (Campos, $2013: 82$ ).

Segundo Campos, ao escrever um poema para uma das páginas com faixas escalonadas em losango, criou o primeiro "poemóbile", que articulava um jogo entre o nome das cores utilizadas no livro (azul, amarelo, vermelho) e as palavras "abre","fecha" e "entre", que sugeriam as opções de manipulação de cada página.

As páginas de Objetos situam-se na confluência de suas experiências anteriores, ainda na Espanha, e o contato com as propostas concretas e neoconcretas brasileiras, podendo-se perceber semelhanças com outras obras, a exemplo do Livro da Criação de Lygia Pape (1959-60). Entretanto, o forte contraste entre as cores, a rigorosa simetria e a dinâmica das diagonais the dão um caráter próprio, seriado, que intensifica a relação entre planos e espaço, e ativados pelo espectador que abre suas páginas.

Pelos três exemplares, verificamos a diversidade de técnicas (xilogravura, linoleogravura, pouchoir, serigrafia), assim como de suportes e diferentes propostas de usos da cor, que mostram algumas identificações e uma abertura a experimentações, presentes nos álbuns de gravura de Julio Pacello.

A aquisição de tais álbuns, mesmo não programada por uma política explícita para a coleção do museu, mostra que os agentes envolvidos (professores do curso, coordenadores do museu) apresentam, por sua formação, gosto, relações sociais e conexões institucionais, uma plataforma estética que mostra-se, mesmo de modo caótico e não intencional, coerente.

Contextualizados, ainda, entre outros álbuns de gravura da coleção, alguns mais atuais, acabam por constituir um segmento museológico da coleção que apresenta desafios e tratamentos comuns, desde sua catalogação e inventário como um bloco autônomo de objetos ordenados, o depósito adequado na reserva técnica (que inclui por vezes caixas, envelopes, capas de materiais diversos das próprias gravuras), a conservação e, evidentemente, os modos de exposição.

Sobre esse último aspecto, podemos exemplificar a expografia realizada para a exposição Variações e Afinidades: obras do acervo do MUnA, organizada em maio de 2014 na sala principal do museu. Foram utilizados os recursos de emoldurar as páginas dos álbuns, individualmente ou em grupo; apresentar as caixas e capas em vitrines sobre módulos; e abrir as lâminas sobre prateleiras (no caso de Plaza) (Figs. I e 2). Ou seja, todas alternativas que impedem a aproximação e fruição do espectador como originalmente pensadas para os álbuns. A preservação das obras, em contexto de exposições, impede a participação ideal do público, transformando-a em uma apreensão mais passiva e tradicional. 

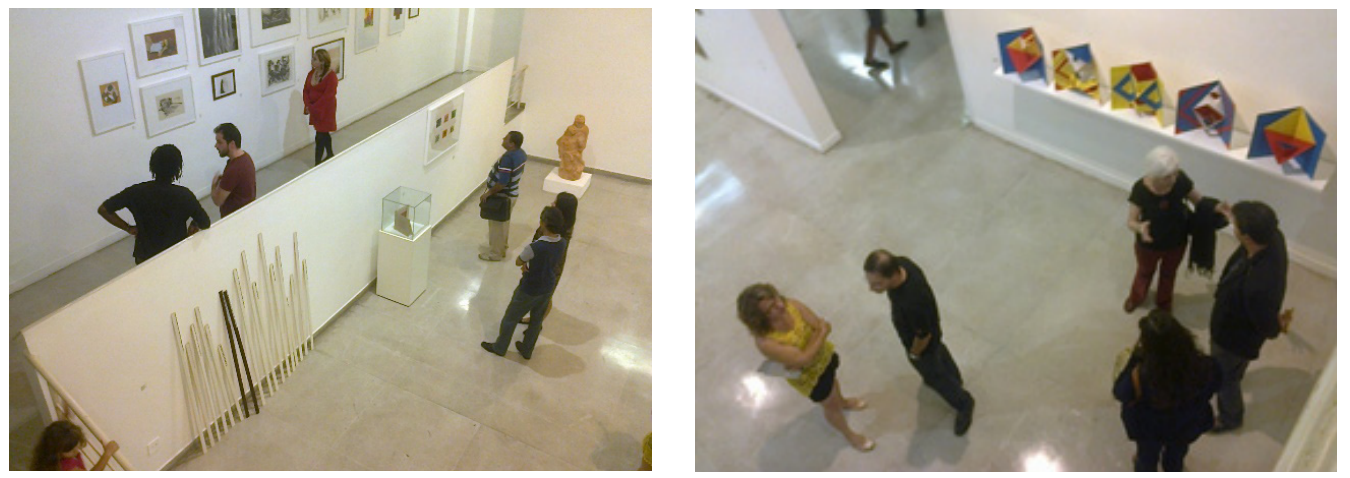

Figs. I e 2.Vistas da inauguração da exposição Variações e Afinidades: obras do acervo do MUnA. Na figura I, no alto, à esquerda, três estampas do álbum de Scliar emolduradas na parede; à direita, na mureta de baixo, o álbum de Mestre Noza está representado pela caixa aberta em uma vitrine e seis estampas montadas em uma só moldura na parede. Na figura 2, algumas lâminas do álbum de Júlio Plaza estão dispostas abertas em uma prateleira. Museu Universitário de Arte, Uberlândia - MG, 20I4. Fotografia:Alex Miyoshi.

Tais desafios, de pesquisa e tratamento, mostram-se um campo de pesquisa fértil e certamente constituem um foco de interesse compartilhado por outras instituições que possuem obras semelhantes, principalmente por tratarem-se de exemplares múltiplos, a natureza intrínseca de tais objetos museais. Seria possível diferenciar as singularidades da sua presença em cada coleção? Essa é uma pergunta que possivelmente emergirá em um futuro próximo, com o avanço das pesquisas sobre nossas instituições.

\section{Considerações finais}

Através desse artigo, pretendemos realizar uma primeira abordagem sobre a presença de álbuns de gravura como segmentos específicos de uma coleção museal, utilizando como estudo de caso a existência de alguns álbuns produzidos pelo editor Julio Pacello na coleção do Museu Universitário de Arte da Universidade Federal de Uberlândia.

Um ponto importante a salientar refere-se à importância de tais álbuns enquanto possibilidade de constituição de acervos regionais, devido ao seu caráter múltiplo, e sua função artística, educativa e sensibilizadora, que se efetiva, nesse caso, em um ambiente universitário entre propostas de ensino, pesquisa e extensão.

Embora produzidos por artistas diferentes, o conjunto das edições demonstra outro tipo de investigação, que trata dos agentes de circulação das obras (impressores, editores, marchands, colecionadores, responsáveis pela formação dos acervos). Isso indica que a significação de uma obra encontra-se além de seu caráter intrínseco, sendo modificada e ampliada pelos diversos contextos por que transita.

É de interesse que relações afetivas, entre técnicos, professores, alunos de universidades e ateliês artísticos, tenham uma importância tão contundente quanto as relações econômicas de comercialização entre galerias, agentes financeiros (como o Banco Central) e a existência de verbas disponíveis de aquisição de obras.

Percebemos que há uma intenção estética, e mesmo pedagógica, que moveu Júlio Pacello a editar seus álbuns, que incluía mesmo séries da História da Gravura no Brasil. Reconsiderar tais aspectos quando esse conjunto migra para o contexto de um museu universitário é reavivar as intenções e somá-las à nova condição.

De fato, através de Scliar, Mestre Noza e Júlio Plaza, entre tantos outros artistas, é possível concluir que seu significado está nessa latência de um aprendizado estético, que nos faz ver que a expressão moderna, seja próxima de uma produção cultural popular, ou da construção abstrata, constrói valores humanos de coexistência, tolerância e diversidade artística, fundamentais para a formação do cidadão autônomo e consciente. 


\section{Referências}

AMARANTE, Leonor. Xilogravura: do cordel à galeria. São Paulo: Metrô, 1994.

BANAT, Ana Kalassa El. A imagem gravada e o livro: as publicações da Sociedade dos Cem Bibliófilos do Brasil, apoximações às poéticas brasileiras entre os anos 40 e 60. Dissertação (Mestrado em Artes). Universidade de Campinas, Campinas, 1996.

CAMPOS,Augusto de. Poesia “entre": de Poemóbiles a Reduchamp. In: FUNDAÇÃO VERA CHAVES BARCELLOS. Julio Plaza: poética. Porto Alegre: Fundação Vera Chaves Barcellos, 20 I3, p. 80-87.

CARDOZO, Joaquim. Scliar. Série Guacha: linóleos e pouchoirs. São Paulo: Acervo, 1974.

CASIMIRO, Renato. Mestre Noza. Recife: Fundaj, Instituto de Pesquisas Sociais, Coordenadoria de Estudos Folclóricos, 200I.

GONÇALVES, Cassandra de Castro assis. O clube de gravura de Porto Alegre: arte e política na modernidade. In: FORUM DE PESQUISA CIENTİFICA EM ARTE, IV. Anais... Curitiba: Escola de Música e Belas Artes do Paraná, 2006.

LEHMKUHL, Luciene; OLIVEIRA, Fabiana Carvalho de. Catálogo de obras do MUnA. UFU/MUNA, fev. 2009.

LEHMKUHL, Luciene. MUnA: um acervo de papel? In: COLÓQUIO DO COMITÊ BRASILEIRO DE HISTÓRIA DA ARTE, XXXIV. Anais... Uberlândia: UFU, 20I4, v.2, p. 967-972.

MINDLIN, José. Julio Pacello e sua obra editorial. São Paulo: Museu de Arte de São Paulo, 1979.

MOTTER, Talita Bueno. Gravura, figuração e política: a obra de Carlos Scliar junto ao Clube de Gravura de Porto Alegre (1950-56). Trabalho de Conclusão de Curso (Artes Visuais). Universidade Federal do rio Grande do Sul, Porto Alegre, 20I 3. MUSEU UNIVERSITÁRIO DEARTE. Inventário 20 I 2: obras do acervo. Uberlândia: MUnA, 2012.

SALVATORI, Maristela. Notas sobre o Clube de Gravura de Porto Alegre. In: ENCONTRO NACIONAL ANPAP, 20. Anais... Rio de Janeiro: UERJ, 20I I, p. 4092-4104. 